\title{
Canadian program targets diarrhea-related child deaths in India
}

A new Canadian program aims to save the lives of about 150000 children in three states in India by scaling up the use of zinc supplementation and oral rehydration salts. The Zinc Alliance for Child Health (ZACH) is a movement of Canadian organizations led by UNICEF Canada and Teck Resources Limited, one of the world's largest producers of zinc.

About $30 \%$ of under-five child deaths globally occur in India, according to United Nations estimates in 2011.

"Thirteen percent, or approximately 215000 , of these child deaths are attributed to complications caused by diarrhea, a sickness that is easily treatable with zinc and oral rehydration salts," says David Morley, president and CEO of UNICEF Canada.

A Cochrane systematic review pub- lished last year showed that zinc supplementation is effective in reducing the duration of diarrhea in children aged six months or more (Cochrane Database Syst Rev 2012;6:CD005436).

The \$5-million, five-year partnership between Teck and ZACH, launched in April, will improve treatment, educate families, caregivers and health professionals about the efficacy of zinc and oral rehydration salts and "strengthen health care systems to help ensure that no child dies from diarrhea in the states of Uttar Pradesh, Madhya Pradesh and Odisham," says Doug Horswill, senior vice president of Teck.

These states have the highest burden of childhood diarrhea in India. A systematic review of 13 randomized trials in developing nations showed a $43 \%$ reduction in all-cause mortality and a $23 \%$ drop in diarrhea-related hospital admissions with the use of zinc (Int $J$ Epidemiol 2010;39:163-9).

In the initial phase, 2013-17, the program aims to save 150000 children's lives. In subsequent years, it hopes to save 50000 per year in the three states.

"The program will also have larger public health implications," says Morley. In addition to the training, supply chains will also be strengthened so health workers and families have reliable access to zinc and oral rehydration salts.

Similar programs were previously launched by UNICEF Canada and Teck in Nepal, Peru, Senegal and Ethiopia. - Soumyadeep Bhaumik, MBBS, Kolkata, India

CMAJ 2013. DOI:10.1503/cmaj.109-4478

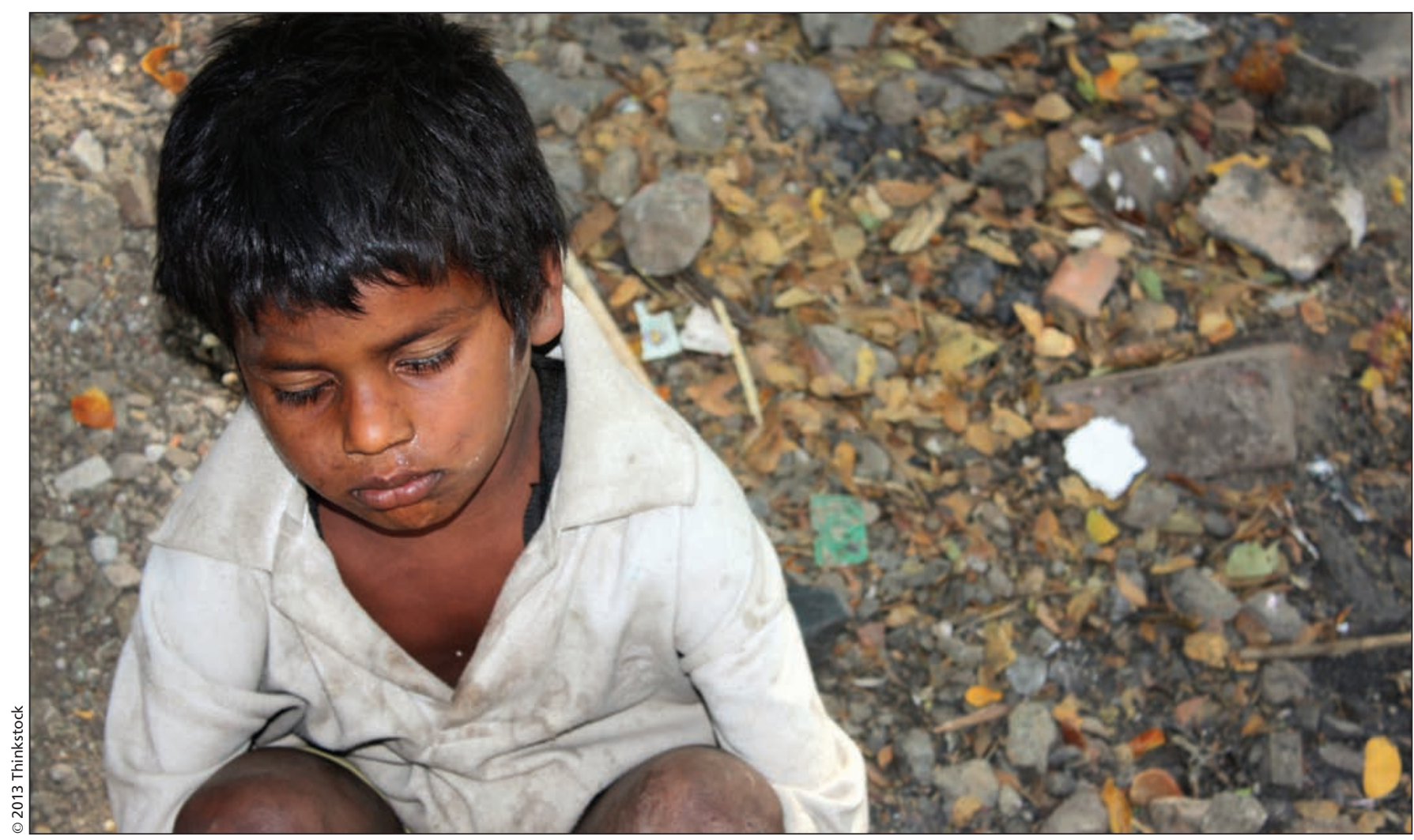

About $30 \%$ of the under-five child deaths globally occur in India, and approximately 215000 of these deaths are attributed to complications caused by diarrhea. 